\title{
Assessing the Impact of Social Innovation Education on Student's Engagement
}

\author{
By Irene Kalemaki ${ }^{1}$, IoannaGarefi ${ }^{1}$, Aristidis Protopsaltis ${ }^{2}$
}

\begin{abstract}
This paper presents the findings of the H2020 NEMESIS project that aims to design, test and validate a consolidated approach for embedding Social Innovation in Education. Social Innovation Education (SIE) is a new educational approach that aims to empower students to take action for a more democratic and sustainable society. During the academic year 2018-2019, eight schools from five European countries applied the NEMESIS SIE framework by involving 56 teachers, 1030 students and 69 community members in a variety of SIE approaches. This paper reports on these attempts with a particular focus on analysing their impact on student's engagement. Data were retrieved through focus groups with 80 people, an online survey to 206 students, interviews, classroom observations and students' narratives. Research findings suggested positive outcomes for students in terms of emotional, cognitive, behavioural and agentic engagement. Findings also showed a positive influence of SIE on the cultivation and progression of students' social innovation competences. These initial findings have the potential to pave the way for more research in the under investigated field of SIE as well as to encourage policies and initiatives for promoting social innovation in education.
\end{abstract}

Keywords: Social Innovation; Education; impact, cognitive, behavioural, emotional, agentic engagement

\section{Introduction}

The advent of 21 st century has raised an increased interest in addressing Education for innovation, entrepreneurship and sustainable development even from the early school years. Many educators, scholars and policymakers agree that the earlier students develop a deep understanding and a mindset conducive to innovation and sustainability, the more prepared they are to thrive in a fast-changing word (Bell 2016).

Various educational approaches have been developed - from student-centred learning to service learning and from entrepreneurship education to active citizenship education offering valuable perspectives and different approaches for addressing through active learning a spectrum of social challenges in an innovative, creative and sustainable way. Within this scope lies Social Innovation Education (SIE). Although Social Innovation (SI) is a well-researched area, SIE research is in its infancy. One of the few peer reviewed studies that explicitly focuses on SIE has been developed by the University of Northampton, in an attempt to design a theoretical framework for embedding SIE in the academic programmes of the University (Alden Rivers, et al. 2015). Kalemaki, et al. (2019) have put forward a learning framework for SIE, as part of the NEMESIS project and provided a comprehensive working definition of SIE. 
According to this definition, SIE is a collaborative and collective learning process for the empowerment and socio/political activation of students to drive positive change no matter their professional pathways. SIE builds students' competences to identify opportunities for social value creation, to form collaborations and build relationships and take innovative action for a more democratic and sustainable society (Kalemaki, et al. 2019).

This definition is focused on the empowering and transformative power of SIE to enhance the individual and collective competences of young people to produce collective outcomes and social value. On this basis, a flexible, non-prescriptive Social Innovation Learning Framework (SILF) was developed for primary and secondary education to guide and inspire the integration of SIE in schools. This paper presents the findings of the first pilot implementation of this SILF in primary and secondary schools in 5 European countries with a particular focus on discussing the impact of SIE on student's emotional, cognitive, behavioural and agentic engagement.

\section{Social Innovation Education}

SIE is a multidimensional and interdisciplinary educational approach that shares principles from various learning theories and educational philosophies which are thought to foster the empowerment, innovation and socio-political activation of students for more democratic and sustainable societies.

To establish a clear understanding of the nuances and the conceptual learning conditions established through SIE, a tree-layers conceptualisation model has been developed to provide clarity on the educational philosophy of SIE and make the intended interventions and the expected learning outcomes comprehensive. The SIE conceptualisation model (Fig.1) consists of the foundational layer which offers the underlying educational philosophy; the middle layer provides the design principles used for the structural elements and the top layer offers some context-sensitive program components that allow SIE to be tailored to different local settings and serve for different interpretations of achieved outcomes.

\section{SIE 3-layers conceptualization model}

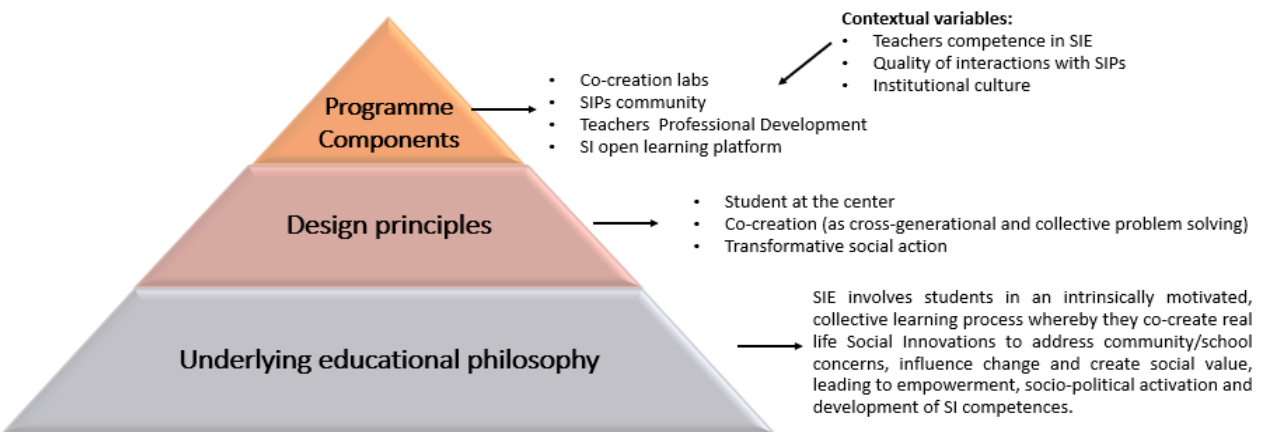

Figure 1: SIE conceptualization model 


\subsection{SIE underlying educational philosophy}

The underlying educational philosophy of SIE can be perceived as a generalized, context independent statement of the learning conditions that characterise the intervention and its purposes. In this respect, the educational philosophy of SIE reflects the idea of involving students in an intrinsically motivated learning process whereby they collectively create, implement and deliver real life social innovations to address local, national or international social issues, influence positive change and create social value. This process can lead to student's empowerment, socio-political activation and development of social innovation competences (Kalemaki, et al. 2019).

SIE combines elements from different educational approaches (i.e. youth activism, enterprise education) as it aspires to:

- combine action with activism

- personal development with collective efficacy

- entrepreneurial mindsets with democratic values and

- individual competences with collective competences

so as to prepare and empower young people to cooperate with each other achieving common goals and driving positive change for a more democratic and sustainable society.

\subsection{Design Principles}

Design principles offer the middle layer of SIE and they represent generalized and relatively stable approaches to establish conceptual learning conditions. The design principles used for the conceptualisation of SIE include i) student at the centre, ii) cocreation and ii) transformative social action. These principles are strongly related to the empowerment and socio-political activation of students assumed to lead to greater levels of student's engagement.

SIE reflects a student-centered approach to learning that shift the focus of instruction from the teacher to the student (Jones 2007). This principle transforms the dynamics of knowledge production to enable students to be the active and self-determined producers of their own learning, whether individually or collectively. It builds on the constructivist learning theories (Piaget 1980) putting students' interests first and on the selfdetermination theory (SDT) that supports student empowerment, engagement and motivation (Litalien, et al. 2017; Reeve 2012). SDT views children as active participants in their environment who seek to fulfil three basic needs: autonomy, belonging and competence (Deci \& Ryan 2002). The facilitation and enhancement of these processes hold the power eventually to lead to student's empowerment (McQuillan 2005) which is what SIE strives to achieve.

The second design principle of SIE is related to co-creation. Co-creation is conceptualised as a collaborative, reciprocal process through which students together with teachers and other actors contribute equally to curricular conceptualization, decision-making, implementation, investigation, or analysis (Bovil, et al. 2016). As a concept, co-creation is strongly related to students' commitment, engagement and participation (Hart 2008) as it indicates a process where students become co-creators of their learning experience on a new basis of collective problem-solving towards tackling issues that matter to them. Assuming thus co-creation as a process of intergenerational interactions, equal participation, mutual decision making and collaborative problem solving towards a 
common goal (Jones \& Perkins 2005), co-creation is considered as a process that can empower students by making their voice heard and valued. The type and quality of the cocreation relationships between young learners and adults, play a significant role in students' behavioural, cognitive, emotional and agentic engagement (Archambault, et al. 2009; Fredricks, et al. 2004; Jimerson, et al. 2003; Reeve 2012) and especially in the development of agency, sense of belonging, competence, discourse and civic efficacy (Mitra \& Serriere 2012). When students feel that they are being valued and respected by adults, they start developing a sense of ownership and attachment to their school, which has the capacity to increase student engagement and self-empowerment. This creates a direct link to the work of Reeve (2012) on agentic engagement which is closely related to the concept of building autonomous learners who proactively attempt to create, direct, enhance, and personalize the conditions of their learning (Reeve 2012).

The last design principle is the principle of transformative social action, which is related to existing citizenship education curricula aiming at increasing student's engagement and future civic engagement. Although citizenship education has been extensively researched (Wood et al. 2013), it is still not consistently understood given the various forms that it takes ranging from educational activities that assist young people to become 'personally responsible citizens, 'participatory citizens' and 'justice-oriented' citizens (Woods et al. 2018). The concept of a "justice-oriented" citizen (Westheimer \& Kahne 2004) relates to citizens who hold a desire to improve society and therefore is well aligned with the definition of SIE, provided earlier, which is focused on the "socio-political activation of learners to drive change for more democratic and sustainable societies". Therefore, SIE argues that education that aims to nurture "justice oriented" citizens should focus on equipping students with the ability to critically analyse society and address social issues and injustices (Woods et al. 2018) providing students with opportunities to practice more active forms of citizenship which can foster future civic participation (Davies et al. 2013; Kahne \& Sporte 2008). On this basis, SIE empowers students to advocate change with a strong collective focus seeing private responsibility as collective responsibility, addressed through collaborative problem-solving fostering thus feelings of agency, belonging, competency and collective efficacy.

\subsection{Programme components}

The top layer of SIE includes a set of flexible programme components for assisting teachers to comprehend, adapt and apply SIE while offering a structured, but non prescriptive, guiding methodology. The main programme component for applying SIE is the "Co-creation lab" which facilitates the establishment of collaborative relations among students, teachers and other relevant actors on a new basis of critically and collectively addressing challenges for making their communities more sustainable. A Co-creation lab reflects the design principles presented above as it indicates a student led process that involves inter-generational collaboration with a strong collective focus towards bringing positive change either outside or inside the school community.

Additional top layer components, include an open learning platform provided to teachers as a tool for management, storing and communication; a pool of Social Innovation Practitioners (SIPs) acting as mentors for students; support material and guidance for teachers' professional development and organisational change. 
In sum, the activation of these programme components (inputs) are assumed to lead to specific outputs, outcomes and impacts as a result of the learning conditions created by the design principles and overall philosophy of SIE.

\section{Method}

A realistic evaluation approach was employed to evaluate SIE by examining how students were impacted by their involvement in the design, co-creation and implementation of social innovation projects. The realistic evaluation (Pawson \& Tilley 1997) was chosen given the multi-disciplinary, context sensitive and multi-faceted learning approach followed in SIE considering that traditional methods of evaluation (such as grading systems, etc.) are not well-suited for such multi-modal learning formats (Hernandez 2016).

Realistic evaluation goes beyond "what happened" and towards understanding "why it happened" providing answers on 'what works, for whom and in what circumstances' (Pawson \& Tilley 1997). The effectiveness of the measure is contingent on the context in which it is introduced, and also, what works to produce an effect in one circumstance will not produce it in another (Tilley 2000). This approach seems well suited as it goes beyond answering the more familiar yes or no question of evaluations, but instead it traces the limits of when and where an intervention is effective.

\subsection{Subjects}

During academic year 2018-2019 five primary schools, a school offering primary and secondary education, an upper secondary school and a VET school participated in the pilots involving 56 teachers, 1030 students, 48 parents and 69 local community actors (external agents) from 5 different European countries (GR, FR, ES, PT, UK). All subjects were volunteers and had no previous experience with SIE. Teacher participants received training and supporting materials (guides) in implementing the SIE approach.

Table 1: Participation stats

\begin{tabular}{|l|c|c|c|c|c|c|}
\hline & Teachers & $\begin{array}{c}\text { Pupils } \\
\text { All }\end{array}$ & $\begin{array}{c}\text { Pupils } \\
\text { Co-Lab }\end{array}$ & $\begin{array}{c}\text { Parents in } \\
\text { Co-Lab }\end{array}$ & $\begin{array}{c}\text { External Agents } \\
\text { in Co-Lab }\end{array}$ & TOTAL \\
\hline Male & 6 & 502 & 156 & 6 & 23 & $\mathbf{5 3 1}$ \\
\hline Female & 50 & 528 & 203 & 27 & 46 & $\mathbf{6 2 4}$ \\
\hline TOTAL & $\mathbf{5 6}$ & $\mathbf{1 0 3 0}$ & $\mathbf{3 5 9}$ & $\mathbf{4 8}^{1}$ & $\mathbf{6 9}$ & $\mathbf{1 1 5 5}$ \\
\hline
\end{tabular}

\subsection{Tools}

The evaluation tools employed were:

- An online survey answered by 57 people (i.e. teachers, parents, social innovation practitioners and community actors) involved in the pilots

- Realist focus groups and interviews with 80 people involved in the pilots

- Pre and post assessment questionnaires whereby students self-assessed the level of development of their competences

\footnotetext{
${ }^{1}$ Some schools have not provided gender data for parents.
} 
- Narratives, short stories and drawings of students granting them with the opportunity to freely express their opinions and perceptions

- Classroom observations and discussions with students

The objectives of the evaluation have been to assess the impact that SIE had on student's engagement and competence development as well as on teachers' knowledge and skills towards SIE. This paper is only focused on the impact of SIE on student's engagement.

\subsection{Design}

The SIE approach was realised with the use of co-creation labs. Co-creation labs were open innovation and learning environment where different stakeholders such as teachers, students, parents, social innovation practitioners and/or other community actors collaborate towards a common goal: to create new knowledge, achieve a clear understanding towards social innovation and develop relevant skills and values by participating in the conception, design and development of social innovation projects. In their majority co-creation labs were conceived as part of extra-curricular activities, that were implemented in school premises outside school hours. However, in some pilot schools SIE was embedded in the curriculum of specific subjects. In terms of participants, all co-creation labs were composed of students, teachers, parents, social innovation practitioners and local community actors. Co-creation lab teams engaged in an iterative process of thinking, reflecting, researching and empathising to deeply understand the situations in which they find themselves, and use that knowledge to take action to improve those settings. In particular, SIP's had an essential role to play in terms of inspiring and guiding the pupils, they acted as mentors (26), as collaborators (18) or as experts (14) spending quite a lot of contact time with the groups. The time spend in co-creation labs, varied among the schools depending the schools, the teachers and the projects. However, their contribution was not one of the measured variables for this study. The following figures (Fig. 2 and Fig. 3) present the role of SIPs and their level of involvement.

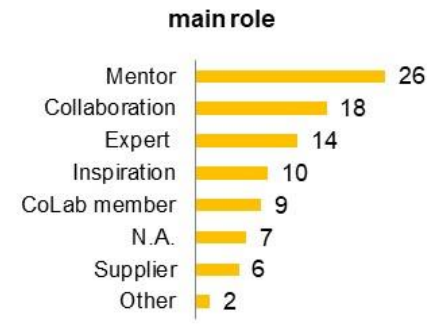

Figure 2: SIP's main roles

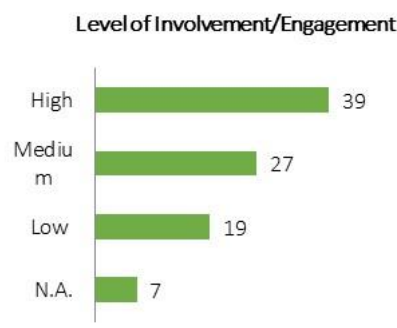

Figure 3: SIP' engagement involvement

Idea generation and democratic decision-making techniques were used to facilitate productive and collective collaborations. As a result, 18 diverse social innovation projects were developed ranging from public campaigns and advocacy actions for clean air; collective actions to improve the school playground and make it more inclusive and sustainable; innovative products to tackle loneliness and isolation; video campaigns to tackle gender violence etc. 


\section{Findings and Discussion} levels:

The impact of SIE on student's engagement was explored and analysed in four

- Emotional engagement (Fredricks et al. 2004) in terms of how students identify with their school which includes their sense of belonging, valuing, or a feeling of being important to the school (Christenson et al. 2012; DeVito 2016).

- Cognitive Engagement which relates to students' psychological involvement in the learning processes and includes perceptions of competency, willingness to engage in effortful learning and task-oriented goals (Archambault et al. 2009; Reeve 2012).

- Behavioural engagement which relates to involvement in the academic environment, including both academics and extracurricular activities (DeVito 2016).

- Agentic engagement, which is connected with autonomous students who proactively attempt to create, direct, enhance, and personalize the conditions and circumstances of their learning (Reeve 2012).

\subsection{The Impact of SIE on student's emotional engagement}

The results showed that SIE had a major effect on the affective domain of students, which was translated into an increase in their emotional engagement for school. In all pilot schools, findings from the focus groups, and interviews showed that students involved in co-creation labs felt more empowered, valued, and important for their school and community. For instance, quotes like NEMESIS gives you a voice and lets you make decisions (Student, UK) was a regular occurrence.

Investigating and analysing the reasons behind these feelings of self-empowerment, a clear connection with the new and redefined relationships that were introduced as part of the co-creation labs was evident. Particularly, in co-creation labs students worked with adults (i.e. teachers, parents, SIPs, community stakeholders etc.) on a completely re-defined basis of equal participation, decision making and collective action towards achieving a common goal. According to students, this experience was entirely new. It was something different from what we are used to do.... working alongside teachers, other adults. It was a different experience (student, Portugal). I did not know what had to be done... when teachers said what are your ideas, I was very surprised because I thought that it was the adults who were going to say the ideas and we who were going to say yes or no (Student, Portugal).

\section{Quality of student- adult relations}

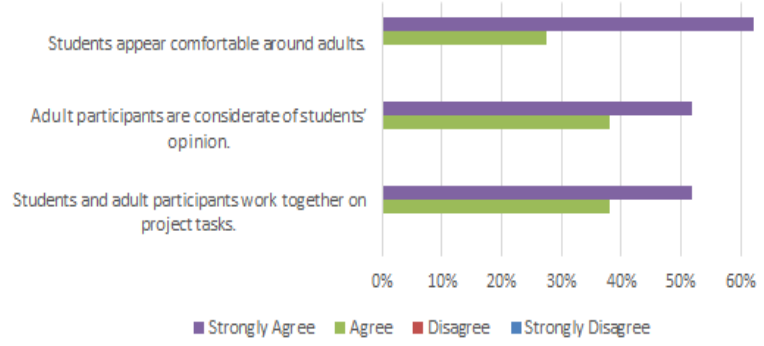

Figure 4: Student-adult relations 
Also, the type and quality of relations developed among students and adults were investigated and according to the findings $(n=29$, Fig. 4$)$ it was evident that collaborative and respectful relationships were developed enabling students to freely express their views and opinions.

Through SIE students realised that they have a say among adults which made them feel valued and important. Contrary to the usual hierarchical relationships among children and adults in a school setting, the core values of SIE changed the relationship landscape by giving an extended voice to students, making them feel like they were not being treated as "children" but as persons who have both a say and the skills to achieve their goals. It is like getting out of the classroom, it's more real. We are not treated as simple kids but as persons... if I think about the future that's the kind of situation, we will be facing... dealing with different kinds of people that you may not know very well but you'll need to collaborate (pupil, Spain). During Nemesis cafés, the pupil becomes a real person ... they say no, they discuss things, they even propose impossible things (Teacher, France).

Another factor that led to increased sense of empowerment and as an extension, emotional engagement, was the student-centred approach. Particularly, students said: NEMESIS gave us more independence to do things that we idealized. More capacity to carry out our projects and our ideas (Student, Spain); I would say that it is a project with which you gain independence and that you perceive a work environment such as next year in the faculty where you often have an objective but not a protocol (Student, Portugal).

The interviews revealed that an additional factor that increased student's emotional engagement was the social orientation of the social innovation projects aiming to change a given situation for the benefit of a community group either inside or outside the school. Particularly, teachers pointed out that one of the most important benefits of SIE is that it enables students to feel certain that they make a difference, which in turn increases their self-empowerment. For instance, a teacher from Greece said: If it was about creating a business, I think that it wouldn't have the same emotional charge. It becomes even more evident these days, that we need to create dignified ways of contribution. Putting children into such a logic brings a great emotional charge. Another teacher from Greece underlining the social aspect of SIE argued: This social dimension strengthens the project. Students understood that this is something new in their lives, and the school doesn't not provide such learning. They were interested in it because they wanted to contribute. The idea that although I am just a kid but I can make another child feel better, with my contribution made them feel important.

Finally, an additional factor that led to student's emotional engagement was related to the creation of a strong sense of belonging and connectedness with their communities that was built as part of their involvement towards solving real life problems on a collective basis and beyond their classrooms. According to teachers and parents interviewed, students perceived that the social innovation projects were of the whole community, it was not just about themselves. The supportive and trusting relationships that were formed with adults and peers during the co-creation labs brought everyone closer to the projects and strengthened their sense of collective efficacy. Students themselves indicated that their involvement in cocreation labs made them feel that they can make a difference together. Teachers noticed that the more they opened up to new collaborations with community actors the more horizons opened up and this was very helpful in increasing student's engagement and making them feel part of a team. I think they have been making an increasingly bigger group. They said, it is our 
space and we form a work team that we have to worry about... They have made a group of concern ... of social preoccupation said a Teacher from Spain.

\subsection{The Impact of SIE on student's cognitive engagement}

Regarding the impact of SIE on students' cognitive engagement the results showed that SIE increased cognitive engagement as students developed a deep understanding of how their activities and learning during the co-creation labs could bring a tangible outcome. Co-creation labs enabled learning to be linked to students' lives and experiences and, in this way, students were able to understand the real-world value of the tasks performed which had a direct impact on their cognitive engagement. Understanding the real purpose of their learning, students have taken ownership of their ideas to drive their social innovation projects forward and become more motivated to perform different tasks about them because it felt personal, important and relevant. The tangible, real life purpose and outcomes were motivating and increased engagement as most teachers noted. For example, a teacher from Portugal pointed out that It was a problem that they detected and something they feel is their own I can now see my student's willingness and passion to perform activities that in the past were feeling bored to do (i.e. writing, reading). While a teacher from Greece mentioned: Now they suddenly all want to become "readers" and "writers" for lonely and disconnected people because there is a real purpose behind; while a Spanish student said: Maybe it's the dynamic of the project, also that we want to make the it more ours.

\subsection{The Impact of SIE on student's behavioural engagement}

The results showed a positive impact of SIE on students' behavioural engagement. The engagement was twofold; students involved in co-creation labs not only increased their involvement in the classroom but also improved their behaviours with other children. It was evident according to teachers that SIE helped especially the shy students to increase their confidence to express their ideas. I have seen students that were more constricted in the cognitive objects to become more open and to come forward (Teacher, Greece); ...students that normally don't speak now look completely different ... they have ideas, ask questions... they did not have a critical spirit (Teacher, Portugal); I've seen other facets of students... more talkative, proactive, creative ... less shy...why, maybe not feeling classroom pressure (Teacher, Portugal).

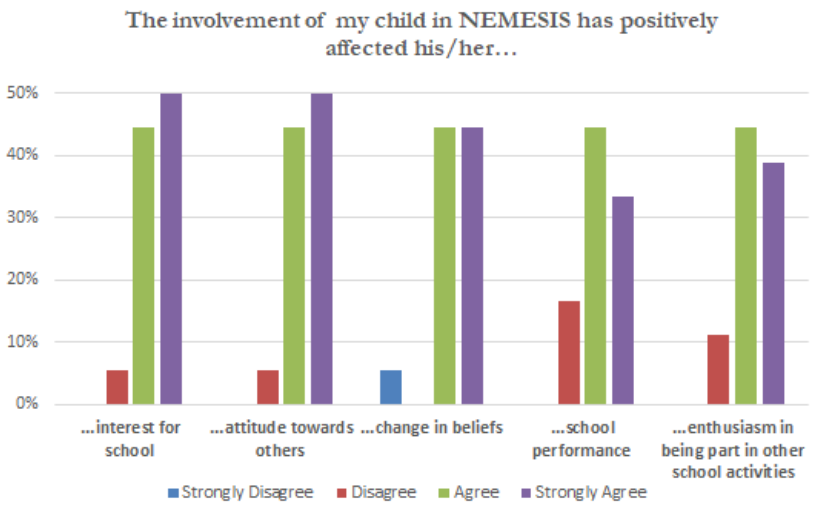

Figure 5: Parents reflection 
These findings were corroborated by the analysis of the online questionnaire to parents $(n=18)$ as shown in Figure 5. The majority of parents involved in the co-creation labs noticed the positive effect on children's attitude towards others, as well as on their overall interest and enthusiasm in participating in school activities and in class.

The results also revealed that SIE had a positive impact on how students behave towards their peers. According to a teacher from Spain: ...it has been especially positive for children with social problems. For some children it has been a path of integration, of enjoyment, of relaxation (School Director, Spain).

\subsection{The Impact of SIE on student's agentic engagement}

Regarding the agentic engagement, the results showed that a strong sense of agency was observed in students involved in co-creation labs. The increase in agency was seen in two different levels: i) students became more proactive, taking initiatives, designing and making constructive suggestions and ii) students increased their willingness and efforts to influence change.

This change is possibly attributed to various factors but an important one relates to the growing sense of "being heard" that was reported by most students. Another factor that contributed to agency is the strong sense of ownership and enthusiasm that students developed towards their social innovation projects. The words of a participating student are indicative emphasising that: This is our project. We are making the decisions. Before that, they were told what to do. A sense of agency was also recorded in cases where students attempted to influence change in given situations either inside or outside their school. As teachers noted, this sense of agency was gradually developed. Especially when students understood that their ideas would turn into action and that they weren't talking about theoretical things, they changed their minds and they gradually became more proactive and determined to achieve their goals. According to a teacher from Greece, When kids decided to send a letter to the Mayor, they thought he may not respond...but what they said was, we'll make sure he does; "We will improve the school. And I will be helping to do it. We will change it. If we all assume our responsibility, we will make it! I believe it! (student, Portugal). Furthermore, the collective effort and purpose of the co-creation labs is also a decisive factor towards fostering student's agency. As said by one of the students in Portugal, I felt that my participation and my friends' could change the world.

In general, the findings indicated that SIE has a strong potential to increase students' engagement and offer a positive learning experience. These findings are aligned with other studies (Mitra \& Serriere 2012) that have investigated student voice initiatives on the basis of cross-generation collaborations to address problems in schools, concluding that when students felt that they are being valued and respected by adults, their engagement was increased and was connected with the development of their agency, sense of belonging, competence, discourse and civic efficacy (Mitra \& Serriere 2012).

\section{Conclusions}

The current study revealed that SIE holds a strong potential as an educational approach to increases students' several level of engagement. More precisely:

- In terms of emotional engagement, SIE makes students' voices heard, valued, and acted 
upon by adults. As an extension a feeling of being important is generated leading to intrinsic motivation, confidence, sense of belonging and self-empowerment.

- In terms of cognitive engagement, SIE's student-centered approach, enables students to link their projects to their lives and in this way to understand the real-world value of their learning. In this way they develop a sense of ownership towards their learning leading to cognitive engagement.

- In terms of behavioural engagement, SIE cultivates a sense of belonging as members of a group that supports, accepts, and respects one another. In this way, students work collectively and feel they are respected by adults which increases participation, effort and positive attitude towards school.

- In terms of agentic engagement SIE empowers students to make decisions and influence changes in their own schools and community. It supports their autonomy and confidence and enable them to see clearly that they can have an impact on their learning but also on their lives, increasing thus their sense of agency.

Finally, the results from the evaluation of SIE on students were similar among different countries. What was different was mainly the impact of NEMESIS on teachers (which is not covered by this manuscript). Teachers presented a different level of understanding and performance which was highly influenced by context specific variables (i.e. national educational system; instructional style, school culture and flexibility; cultural factors etc.) Therefore, in some countries (Greece, Portugal) teachers were influenced more than in other countries (UK) where pedagogies like SIE have already been introduced in school curricula.

\section{Acknowledgements}

The NEMESIS project has received funding from the European Union's Horizon2020 research and innovation programme under grant agreement nr 688221. Any opinions, findings, and conclusions or recommendations expressed in this paper are those of the author(s) and do not necessarily reflect the views of the European Union.

\section{References}

Alden Rivers, B., Armellini, A., Maxwell, R., Allen, S., \& Durkin, C. (2015). Social innovation education: towards a framework for learning design. Higher Education, Skills and Work-based Learning, 5(4), 383400 .

Archambault, I., Janosz, M., Morizot, J., \& Pagani, L. (2009). Adolescent behavioral, affective, and cognitive engagement in school: Relationship to dropout. Journal of school Health, 79(9), 408-415.

Bell, D. (2016). Twenty-first Century Education: Transformative Education for Sustainability and Responsible Citizenship. Journal of Teacher Education for Sustainability, 48-56.

Bovil, C., Cook-Sather, A., Felten, P., Millard, L., \& Moore-Cherry, N. (2016). Addressing potential challenges in co-creating learning and teaching: Overcoming resistance, navigating institutional norms and ensuring inclusivity in student-staff partnerships. Higher Education, 71(2), 195-208.

Deci, E., Ryan, R., \& . (2002). An overview of self-determination theory. In An overview of self-determination theory (pp. 3-33). Rochester: University of Rochester Press.

Fredricks, J. A., Blumenfeld, P. C., \& Paris, A. H. (2004). School engagement: Potential of the concept, state of the evidence. Review of educational research, 74(1), 59-109. 
Hart, R. (2008). Stepping Back from “The Ladder": Reflections on a Model of Participatory Work with Children. In A. Reid, B. Jensen, J. Nikel, \& V. Simovska, Participation and Learning. Perspectives on Education and the Environment, Health and Sustainability (pp. 19-31). New York: Springer.

Hernandez, M. (2016). Evaluation Within Project-Based Learning. Retrieved from https://www.edutopia.org/blog/evaluating-pbl-michael-hernandez.

Jimerson, S. R., Campos, E., \& Greif, J. L. (2003). Toward an understanding of definitions and measures of school engagement and related terms. The California School Psychologist, 8(1), 7-27.

Jones, K. R., \& Perkins, D. F. (2005). Determining the quality of youth-adult relationships within communitybased youth programs. Journal of Extension, 43(5), 1-10.

Jones, L. (2007). The Student-Centered Classroom. Cambridge: Cambridge University Press.

Kalemaki, I., Garefi, I., Kantsiou, S., Diego, I., Protopsaltis, A., \& Wall, J. (2019). Towards a learning framework for Social Innovation. 7 EMES International Research Conference on Social Enterprise. Sheffield.

Litalien, D., Morin, A., Gagné, M., Vallerand, R., Losier, G., \& Ryan, R. (2017). Evidence of a continuum structure of academic self-determination: A two-study test using a bifactor-ESEM representation of academic motivation. Contemporary Educational Psychology, 51, 67-82.

McQuillan, P. (2005). Possibilities and pitfalls: A comparative analysis of student empowerment. American Educational Research Journal, 42, 639-670.

Mitra, D. L., \& Serriere, S. C. (2012). Student Voice in Elementary School Reform: Examining Youth Development in Fifth Graders. American Educational Research Journal, 49(4), 743-774.

Pawson, R., \& Tilley, N. (1997). Realistic evaluation. London: Sage.

Piaget, J. (1980). The psychogenesis of knowledge and its epistemological significance. In P. Palmarini, Language and Learning (pp. 23-34). Cambridge: Harvard University Press.

Reeve, J. (2012). A self-determination theory perspective on student engagement. In S. Christenson, Handbook of research on student engagement (pp. 149-172). Boston: Springer.

Tilley, N. (2000). Realistic Evaluation: An Overview. Founding Conference of the Danish Evaluation Society.

Wood, B. E., Taylor, A., Atkins, A., \& Johnston, M. (2018). Pedagogies for active citizenship: Learning through affective and cognitive. Teaching and Teacher Education, 75, 259-267. 